\title{
Fetal drug syndromes
}

\author{
NEIL GORDON \\ M.D., F.R.C.P. \\ Booth Hall Children's Hospital, Manchester
}

\begin{abstract}
Summary
Certain drugs which affect fetal development are considered. Phenytoin taken during pregnancy may result in infants who remain mentally and physically retarded, with abnormal craniofacial appearance and limb defects. A boy with such a syndrome is reported. Trimethadione is another drug which has been said to be teratogenic, and to cause a typical phenotype which is described. The fetal alcohol syndrome is now well recognized and has similar features to those related to anti-epileptic drugs taken during pregnancy. A high level of suspicion of possible associations between congenital defects and drugs must be maintained.
\end{abstract}

\section{Introduction}

Among children who are mentally handicapped there are a number whose appearance is strikingly abnormal. When faced with such a problem the most likely explanation may well be a chromosome abnormality which has caused an interference with the development of various tissues of the body. Alternative explanations include endocrine and toxic causes, and the latter may account for a number of such children whose condition remains undiagnosed. There must surely be a variety of drugs taken by a mother during pregnancy which may affect fetal development in this way, and anti-epileptic drugs are an example.

\section{The fetal phenytoin syndrome}

It is well established that patients with epilepsy on treatment with phenytoin can develop coarsening of the features so that it is often easy to recognize at a glance someone who is on this treatment. Now there have been a number of reports of infants born to mothers who have taken phenytoin sodium during the pregnancy and the infants have presented sufficiently characteristic appearances to suggest a syndrome. Syndromes depending mainly on craniofacial anomalies can often be hard to identify, particularly for those with poor visual memories. In one paper on the 'fetal hydantoin syndrome' (Hanson and Smith, 1975) one of the children had been previously reported as an example of the Coffin-Siris syndrome (Weisswasser et al., 1973).

This syndrome consists of absence of the nails of fingers and toes, growth deficiency, mental retardation with coarse features, sparse scalp hair and hypertrichosis. The craniofacial features include heavy eyebrows, bulbous anteverted nose, small teeth, full lips and a broad mouth (Coffin and Siris, 1970). Children described by Senior (1971) with short stature, small toe nails, shortened fifth fingers and broadened nose and mouth have been considered a possible variant of the Coffin-Siris syndrome.

A number of findings among the children born to mothers taking phenytoin during pregnancy have 은 been reported. There is defective growth and mentaf $\vec{\varphi}$ retardation, and limb defects including hypoplasiar. of phalanges and nails, finger-like thumbs anf variations in palmar creases and dermatoglyphics. The craniofacial appearances are characterized by a broad low nasal bridge, epicanthic folds, short upturned nose, hypertelorism, ptosis, strabismus, slightly malformed and low set ears, wide mouth with prominent lips, and variations in head size and shape (Hanson and Smith, 1975).

Among these infants some particular anomalies have been stressed, such as hare lip and cleft palate (Meadow, 1968), digital hypoplasia (Barr, Poznanski and Shmickel, 1974), a combination of digital hypoplasia, diaphragmatic herniae and coarsening of the facies (Barry and Danes, 1974) and a recognizable grouping of congenital heart disease, cleft lip and palate, trigonocephaly and microcephaly, and a variety of minor anomalies such as hypertelorism, low set ears, short neck and bilateral transverse palmar creases (Speidel and Meadow, 1972). There is no doubt that phenytoin is an effective antiepileptic drug, but it does have numerous side effects and perhaps there is a correlation between these two facts.

This patient is reported as an example of the fetal phenytoin syndrome to add to those which have already been published.

S.D., a boy, was born in June 1972 by normal vertex delivery at 38 weeks. His mother was a 
30-year-old primigravida who had suffered from epilepsy since the age of 16 years. During the pregnancy she had been on treatment with phenobarbital $30 \mathrm{mg}$ twice/day, and phenytoin sodium $100 \mathrm{mg}$ twice/day. Recurrent ante-partum haemorrhage occurred from the 32nd week onwards, but there were no other problems. A seizure occurred during the first stage of labour. The mother's serum folic acid level was within normal limits $(5 \cdot 7 \mathrm{ng} / \mathrm{ml})$ when estimated soon after the birth.

The infant needed no resuscitation but a few hours after birth he started to vomit and there was a low dextrostix reading. No abnormalities were found on examination and on small regular feeds the dextrostix recorded a satisfactory level. On the 5th day of life several convulsions occurred, one of which started on the left side and was followed by increased tone on this side. The serum calcium was found to be $1.35 \mathrm{mmol} / \mathrm{l}$ and calcium was given orally. Two days later the infant was apathetic and was still having occasional brief seizures, consisting of flexion of the limbs, upward movement of both eyes, often followed by vomiting. There was no response to diffuse light and no definite fixation. He required tube feeding, and had no head control. There was increased flexor tone of the limbs and the tendon reflexes were brisk. The serum calcium was still $1 \cdot 37$ $\mathrm{mmol} / \mathrm{l}$ and so $4 \mathrm{ml}$ of $2 \%$ calcium gluconate was given intravenously. After this the infant's condition improved and the serum calcium rose to $1.78 \mathrm{mmol} / 1$. However, it remained low for several weeks in spite of a brief period of treatment with parathyroid hormone. Investigations at this time showed a normal X-ray of the skull, a normal CSF and an EEG which showed asymmetries but no consistent focal features. Treatment with primidone was also given but with improvement in the clinical condition in was stopped after a few months.

At the age of 3 months the infant was feeding well and putting on weight. There was poor head control but no abnormal increase in muscle tone. No further seizures occurred but a few minor ones were noted at 11 months of age. Walking started about the age of 20 months, but he did not begin to use words with meaning till nearly 2 years of age. He was admitted to hospital for further assessment soon after this.

On examination the main finding was the boy's unusual facial appearance with slight ptosis, broad nose and large mouth (Fig. 1). The incisor teeth were peg-shaped and there was enamel hypoplasia of the teeth. Apart from the retarded development there were no other abnormalities of significance. Tests for metabolic disorders were negative and the EEG showed only a slight excess of slow wave activity for the child's age. Development quotient on the Griffiths Mental Development Scale (GQ) was 65.

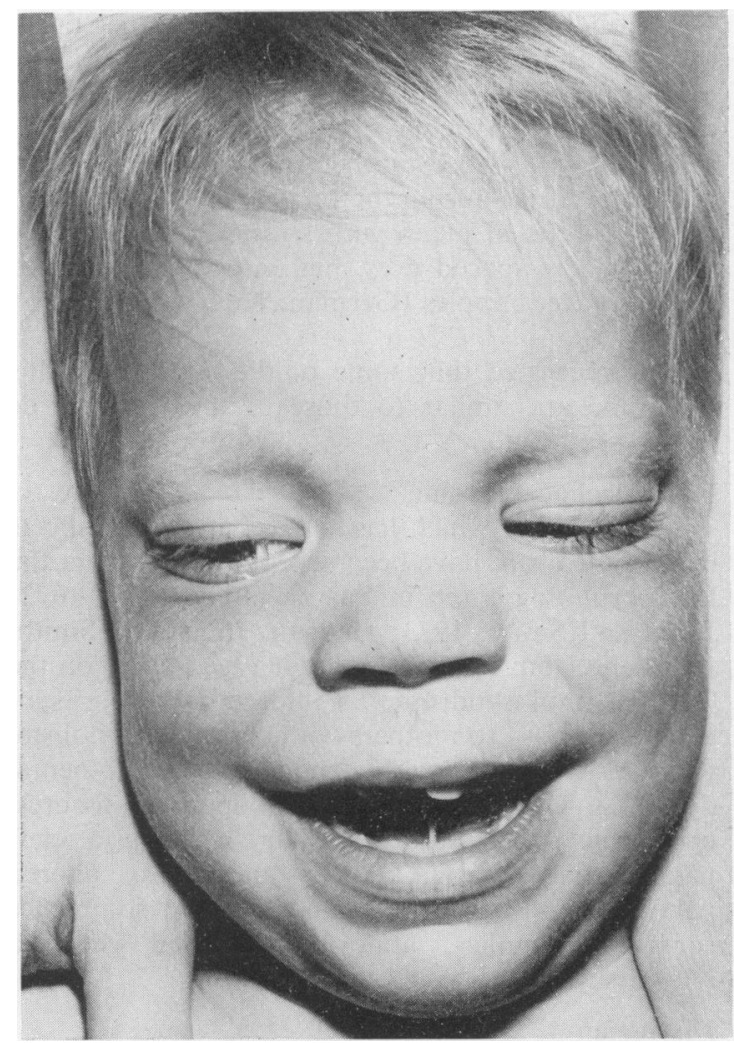

FIG. 1. Facial appearance of child with suspected 'fetal phenytoin syndrome'.

Development continued to be slow, although there was some improvement and when nearly 5 years old the GQ on the same scale was 72. The Speech and Hearing quotient was the lowest at 52. General health remained good and no further convulsions occurred. Other tests that were done and were normal included chromosome studies, estimations of $T_{3}$ and $T_{4}$ because of a low bone age, serum cholesterol, serology for syphilis, virus and toxoplasma tests, further EEGs and X-ray of skull.

\section{The fetal trimethadione syndrome}

Trimethadione is another anti-epileptic drug which has been reported to be teratogenic. Infants born of mothers taking this drug during pregnancy can show developmental delay, speech difficulty, V-shaped eyebrows, epicanthus, low-set ears with anteriorly folded helix, high-arched or cleft palate, and irregular teeth. Intrauterine growth retardation, short stature, microcephaly, cardiac lesions, strabismus, hypospadias, inguinal hernia and simian creases have also been reported (Zackai et al., 1975). 
Although some of the mothers took other drugs as well during the pregnancy trimethadione was the only drug common to this phenotype, and it did occur among patients exposed to trimethadione alone. A girl, whose mother took paramethadione and other drugs during the pregnancy, was retarded and had unusual facies with strabismus, epicanthic folds, widely spaced eyes, high arched palate, and widely spaced nipples (German, Kowal and Ehlers, 1970).

It is suggested that some of the features of this syndrome are similar to those of the Cornelia de Lange syndrome.

\section{Fetal alcohol syndrome}

Another drug which has somewhat similar effects is alcohol. There have been several reports from the Dysmorphology Unit in Seattle (Jones et al., 1973; Jones and Smith, 1973; Hanson, Jones and Smith, 1976) and from France (Lemoine et al., 1968) on the 'fetal alcohol syndrome'. Children with this syndrome are born to mothers with chronic alcoholism. Features include growth deficiency, developmental delay, microcephaly, short palpebral fissures, epicanthic folds, ptosis, maxillary hypoplasia, cleft palate, micrognathia, joint anomalies, altered palmar crease patterns, small nails and sometimes cardiac anomalies, abnormal external genitalia and hirsutism.

\section{Discussion}

All these various syndromes have features in common and as the children are abnormal at birth there must be a disorder of embryogenesis or of fetal development. The presence of such features as abnormal palmar creases and the type of cerebral deformity (Jones and Smith, 1973) suggests that the damage occurs before the eightieth day of gestation. In the case of the fetal alcohol syndrome this may be due to ethanol toxicity or poisoning by one of its metabolites. On the other hand the ova may have been damaged before conception; and these mothers are exposed to a number of 'high-risk factors' such as smoking, malnutrition and social handicaps (Kessel, 1977).

Similarly, phenytoin, trimethadione and/or their metabolites may have toxic effects on morphogenesis but there are other possibilities. Anti-convulsant drugs such as phenytoin are known to cause folic acid deficiency and this may cause malformations (Speidel and Meadow 1972). However there is no definite evidence of consistent folic acid deficiency among the mothers of these children (Hill et al., 1974). Genetic factors must be considered leading to both the epilepsy and the malformations (Fedrik, 1973), and the effects of the seizures themselves cannot be ignored (Monson et al., 1973; Shapiro et al., 1976).
The risks of an individual mother on treatment 3 for epilepsy having an abnormal baby may be low $\stackrel{\varnothing}{\varrho}$ but there is a possibility of these and other drugs $C$ taken during the early months of pregnancy having $\overrightarrow{\vec{c}}$ a harmful effect on the fetus. This fact must always be considered when investigating a child with congenital anomalies. Prospective studies will be of $\frac{\bar{O}}{\bar{N}}$ most value (Hill et al., 1974) but individual reports $\frac{\vec{\sigma}}{\sigma}$ when there seems to be an association between $\bigcirc$ defects and drugs taken during pregnancy will help to $\%$ maintain a high level of suspicion.

\section{References}

Barr, M., Poznanski, A.K. \& Schmickel, R.D. (1974)৫్ర Digital hypoplasia and anticonvulsants during gestation: 3 . a tetrogenic syndrome? Journal of Pediatrics, 84, 254. ir

BARRY, J.E. \& DANES, D.M. (1974) Anticonvulsants and $\oplus$ congenital abnormalities. Lancet, ii, 48.

Coffin, G.S. \& SIRIS, E. (1970) Mental retardation with $\mathcal{W}_{\infty}$ absent fifth fingernail and terminal phalanx. American Journal of Diseases of Children, 119, 433.

FEDRIK, J. (1973) Epilepsy and pregnancy: a report from the Oxford Record Linkage Study. British Medical Journal, 2, 442.

German, J., Kowal, A. \& Ehlers, K.H. (1970) Trimethadione and human teratogenesis. Teratology, 3, 349.

Hanson, J.W., Jones, K.L. \& Smith, D.W. (1976) Fetal $\stackrel{\mathbb{C}}{3}$ alcohol syndrome. Experience with 41 patients. Journal $\sqrt{8}$ the American Medical Association, 235, 1458.

Hanson, J.W. \& SMITH, D.W. (1975) The fetal hydantoon syndrome. Journal of Pediatrics, 87, 285.

Hill, R.M., VERNIAUd, W.M., HoRNIG, M.G., MCCulde L.B. \& Morgan, N.F. (1974) Infants exposed in utero antiepileptic drugs. American Journal of Diseases of Children, 127, 645.

JoNES, K.L. \& SMith, D.W. (1973) Recognition of the fetal alcohol syndrome in early infancy. Lancet, ii, 999.

Jones, K.L., Smith, D.W., Ulleland, D.N. \& Streissguth, ำ A.P. (1973) Pattern of malformation in offspring of $\varrho$ chronic alcoholic mothers. Lancet, i, 1267.

KesSEL, N. (1977) The fetal alcohol syndrome from the $\frac{0}{3}$ public health standpoint. Health Trends, 9, 86.

Lemoine, P., Harrousseau, H., Borteyru, J.P. \& Menuet, J.C. (1968) Les enfants de parents alcooliques: anomalies? observées: à propos de 127 cas. Ouest Médical, 25, 477.

Meadow, S.R. (1968) Anticonvulsant drugs and congenital $\frac{3}{3}$ abnormalities. Lancet, ii, 1296.

Monson, R.R., Rosenberg, L., Hartz, S.C., Shapiro, S., Heinonen, O.P. \& Slone, D. (1973) Diphenylhydantoin and selected congenital malformations. New England $\delta$ Journal of Medicine, 289, 1049.

SENIOR, B. (1971) Impaired growth and onychodysplasia. Short children with tiny toenails. American Journal of Diseases of Children, 122, 7.

Shapiro, S., Slone, D., Hartz, S.C., Rosenberg, L., Siskind, V., Monson, R.R., Mitchell, A.A., Heinonen, O.P., IDÄNPÄÄ-HEIKKILÄ, J., HÄrö, S. \& SAXÉN, L. (1976) N Anticonvulsants and parental epilepsy in the development of birth defects. Lancet, $\mathbf{i}, 272$.

Speidel, B.D. \& Meadow, S.R. (1972) Maternal epilepsy and abnormalities of the fetus and newborn. Lancet, ii, 839. $\sigma$

Weisswasser, W.H., Hall, B.D., Devalan, G.W. \& Smith, D.W. (1973) Coffin-Siris syndrome. American Journal of Diseases of Children, 125, 838.

ZaCkai, E.H., Mellman, W.J., Neiderer, B.\& Hanson, J.W. (1975) The fetal trimethadione syndrome. Journal of $\square$ Pediatrics, 87, 280. 